\title{
Entre fatos e hipóteses: análise crítica do discurso de notícias de popularização da ciência
}

\author{
Between Facts and Hypothesis: \\ Critical Discourse Analysis of Science \\ Popularization News
}

Fábio Santiago Nascimento*
Universidade Federal de Santa Catarina
Florianópolis - Santa Catarina / Brasil

RESUMO: Este artigo apresenta uma análise crítica do discurso (FAIRCLOUGH, 1992) de notícias de popularização da ciência (PC), enfocando os graus de assertividade e autoridade dos atores sociais representados no relato e discussão de descobertas científicas. A análise compreendeu trinta notícias de PC publicadas nos sites $\mathrm{BBC}$ News e Scientific American. Os resultados confirmam a posição de "insegurança discursiva” do jornalista na PC (MOIRAND, 2003), que utiliza diferentes estratégias discursivas para manter a aparente objetividade do discurso jornalístico. Em contraste, o pesquisador-autor do estudo (e seus colegas) ocupa um papel privilegiado nas notícias, oferecendo explicações "coerentes" e apontando limitações nos estudos reportados. A ciência na mídia, desse modo, é uma autoridade epistêmica que reafirma uma lógica tradicional de produção do conhecimento baseada na (re)construção contínua de hipóteses e teorias.

PALAVRAS-CHAVE: Popularização da ciência; notícias; modalidade; linguística sistêmico-funcional.

ABSTRACT: This article presents a critical discourse analysis (FAIRCLOUGH, 1992) of science popularization (SP) news, focusing on the degrees of assertiveness and authority of represented social actors in their task of reporting and discussing scientific discoveries. The analysis was comprised of thirty SP news from the BBC News and Scientific American websites. The results confirm the position of "discursive insecurity" (MOIRAND, 2003) held by the journalist who uses different discourse strategies to maintain the apparent objectivity of journalistic discourse. In contrast, the researcher-author of the study (and his colleagues) occupies a privileged role in the news, providing "coherent" explanations and pointing out limitations in the reported studies. Hence science in the media is an

* fabiosantiagonasc@gmail.com 
epistemic authority which reaffirms a traditional logic of knowledge production based on a continuous (re)construction of hypotheses and theories.

KEYWORDS: Science popularization; news; modality; systemic-functional linguistics.

\section{Introdução}

Estudos sobre a popularização da ciência (PC) na mídia de massa (MOIRAND, 2003, BEACCO et al., 2002, CALSAMIGLIA; VAN DJIK, 2004) têm evidenciado a importância de se investigar as condiçōes de produção, distribuição e consumo de textos na sociedade e os diferentes papéis e relações sociais constituídos pelas práticas discursivas de PC (CALSAMIGLIA, 2003, p. 143).

Textos de PC não são apenas relevantes para o ensino de escrita acadêmica ou ensino de ciências para pesquisadores em formação (MEDEIROS, 2003, p. 90; PARKINSON; ADENDORFF, 2004), mas também podem influenciar, sobretudo, na constituição da sociedade em termos de identidades, discursos, formas genéricas e decisões políticas e econômicas, ao alimentarem debates relevantes na contemporaneidade. Exemplo disso é a discussão no Brasil (sem consenso da população) sobre as vantagens e as desvantagens dos alimentos geneticamente modificados para a saúde humana (LEITE, 2007).

Em vista de tais questōes, Myers (2003, p. 65) faz uma crítica à visão monolítica e simplista de PC centrada na autoridade dos cientistas (HILGARTNER, 1990, p. 520), argumentando que a PC deve ser encarada como "uma ordem discursiva, um terreno de debates e práticas sociais", um "processo" que envolve uma multiplicidade de gêneros, mídias, discursos e vozes de atores sociais de vários âmbitos da sociedade - por exemplo, acadêmico, legal, jornalístico, linguístico, governamental - (MOTTAROTH; MARCUZZO, 2010). A prática social de PC, desse modo, enfoca a explicação do significado social das descobertas científicas no contexto dos discursos e assuntos em evidência na mídia.

Presumindo uma relação dialética entre texto (prática discursiva) e contexto (prática social), textos de PC são caracterizados por estratégias linguísticas específicas, tais como diferentes tipos de polifonia e intertextualidade (BEACCO et al., 2002; MOIRAND, 2003) que refletem a multiplicidade de discursos do cotidiano que convivem com o discurso científico.

Temas como chuva ácida, biotecnologia de alimentos, fertilização in vitro e aquecimento global são objetos da ciência que migraram da esfera 
científica para a esfera pública por meio de debates promovidos pela mídia (SEGUIN, 2001, p. 196). Nesses debates, os participantes envolvidos (tais como cientistas, multinacionais, governo) recorrem aos discursos da ciência (por exemplo, efeito estufa, preservação ambiental, células-tronco) e a estratégias linguísticas (tais como ambiguidades, paradoxos, metáforas) para construírem suas identidades e definirem seus posicionamentos políticoideológicos nos debates científicos expressos nos diferentes gêneros da mídia (notícias, documentários, entrevistas etc.) que circulam na sociedade (HENDERSON et al., 2007).

No relato e discussão de pesquisas científicas em textos de PC, a responsabilidade pelas informaçôes presentes nos textos é creditada a indivíduos que não pertencem exclusivamente à esfera. $\mathrm{O}$ jornalista, por meio da inserção de vozes de diferentes atores sociopolíticos, parece, desse modo, abdicar de sua responsabilidade de apresentar informaçôes "objetivas" e precisas sobre um tópico científico. Ao mesmo tempo, essa estratégia pode ser vista como um modo do jornalista "dramatizar" o conflito, dando a impressão de que textos de PC refletem a "real” necessidade da população de compreender a relevância e os benefícios das descobertas científicas para a vida cotidiana científica (CALSAMIGLIA; LÓPEZ-FERRERO, 2003, p. 169-170).

Essa dinâmica intertextual é apresentada na análise do gênero notícia de PC descrita em Désirée Motta-Roth e Cristina dos Santos Lovato (2009), com uma representação esquemática composta de cinco posições enunciativas, tomando por base análises prévias desse gênero (PRATES et al., 2008; MOTTA-ROTH et al., 2008; MARCUZZO, 2008; 2009): o pesquisador responsável pelo estudo reportado; o pesquisador-colega/técnico no assunto reportado/instituição ligado(a) ao assunto reportado, o governo, o público e o próprio jornalista. Dentre essas posições, o papel individual do cientista parece limitado na mídia, pois a lógica científica, baseada em hipóteses e soluções temporárias, colide com a lógica jornalística baseada na busca de "verdades" e rápidas soluções para os problemas correntes na sociedade (CALSAMIGLIA; LÓPEZ FERRERO, 2003, p. 169-170). A prática discursiva de PC é condicionada, portanto, por regras de formação tanto do discurso científico (ênfase na formulação de hipóteses e teorias com base na observação e explanação de fenômenos) e do discurso jornalístico - ênfase na identificação e interpretação de acontecimentos relevantes para a construção de relatos objetivos como forma de atrair atenção e influenciar a opinião pública (HILGARTNER, 1990, p. 530-532). 
Em vista disso, um dos possíveis objetivos comunicativos do gênero discursivo notícia de PC é a produção e/ou manutenção de "fatos sociais" em termos das crenças e princípios subjacentes à prática científica e de proposiçōes acerca da validade dos resultados das pesquisas popularizadas. Para a produção de fatos ou hipóteses, os jornalistas realizam escolhas no sistema linguístico que constroem significados de certeza/usualidade e obrigação/inclinação nos enunciados.

Em termos discursivos, escolhas no sistema de modalidade (HALLIDAY, 2004) nas notícias podem indicar os graus de responsabilidade e comprometimento modal das vozes presentes nos enunciados em relação aos julgamentos de validade (modalização) e autoridade (modulação). O objetivo da presente pesquisa é analisar criticamente o discurso das notícias de PC de forma a compreender como diferentes graus de assertividade e autoridade são expressos linguisticamente nesse gênero discursivo.

Para o desenvolvimento desse objetivo, o presente artigo $^{1}$ está organizado em quatro seçóes. Na primeira seção, discuto a natureza da prática sociodiscursiva de PC. Em seguida, apresento os conceitos teóricos que embasam o estudo. Na terceira seção, descrevo a metodologia empregada e, por fim, aponto alguns dos principais resultados da pesquisa.

\section{Discursos de popularização da ciência}

Em um discurso tradicional, ${ }^{2}$ a PC é vista como uma tradução (ambígua e distorcida) do conteúdo científico do texto original para uma

${ }^{1}$ Este artigo apresenta resultados da pesquisa de mestrado 'GM crops may be harmful to the environment: graus de autoridade e assertividade nas notícias de popularização da ciência (NASCIMENTO, 2011), defendida pelo autor no Programa de Pós-Graduação em Letras da Universidade Federal de Santa Maria, sob orientação da Profa. Dra. Désirée Motta-Roth, coordenadora do projeto PQ-CNPq 2007-2011 Análise crítica de gêneros com foco em artigos de popularização da ciência (no 301962/2007-3), desenvolvido no Laboratório de Pesquisa e Ensino de Leitura e Redação (LABLER). ${ }^{2}$ Utilizo o termo discurso aqui em consonância com a dupla concepção proposta por Gee (2000). Discursos (com D maiúsculo) são os modos particulares de agir, ser, pensar, avaliar em diferentes contextos, enquanto discursos (com $d$ minúsculo) são as instâncias de uso da linguagem (gêneros discursivos) nas práticas sociais, tais como a conversa entre amigos, $\mathrm{o}$ bate-papo na Internet ou a carta ao leitor de revistas. Na perspectiva da ACD, ambos os sentidos do $\mathrm{D} /$ discurso estão interligados, estabelecendo uma relação dialética: as práticas sociais têm reflexo nos usos da linguagem, ao mesmo tempo em que esses usos da linguagem são constitutivos das práticas sociais (FAIRCLOUGH, 1992). 
audiência leiga (PAUL, 2004, p. 32-33). Dois discursos distintos estão envolvidos no processo de "tradução", um pertencente às instituições científicas e outro de domínio público, que mantêm um fluxo de informação linear, partindo do discurso científico da academia - autoridade em ciência - para o público em geral, considerado homogeneamente "ignorante" (MYERS, 2003, p. 266). ${ }^{3}$ Sob a ótica da midiatização da ciência na França, o fato de textos de PC oferecerem versões didáticas do conhecimento científico é percebido negativamente, em razão da menor complexidade conceitual desses textos (BEACCO et al., 2002, p. 278).

Se considerada como discurso de "transmissão didática" (MOIRAND, 2003), a PC parece pressupor três questôes: (1) hierarquização do conhecimento, no sentido de que o conhecimento científico produzido por especialistas é superior ao conhecimento produzido por não especialistas (BEACCO et al., 2002, p. 278); (2) facilitação da linguagem, que é adaptada a fins didáticos por meio de marcadores específicos expressos na forma de definições, exemplos, explicaçôes etc. (BEACCO et al., 2002, p. 278); e (3) objetivo de ensinar e demonstrar, de forma a criar interesse público e conseguir apoio financeiro para a execução da pesquisa, ao invés de conscientizar e promover a cidadania (PAUL, 2004, p. 33). Além dessas características, uma visão tradicional sobre PC carrega a crença de que o conhecimento produzido nos laboratórios não possui aplicação prática na vida diária, sendo considerado apenas um conjunto de "afirmações na forma escrita" que possui valor somente no âmbito acadêmico (MYERS, 2003, p. 266).

Entretanto, vista sob uma ótica contemporânea, a PC se apresenta como um processo muito mais complexo do que se pensava anteriormente. Ao invés da transmissão unilateral do conhecimento científico dos cientistas para o público, a PC é vista como um processo dialético, no qual ciência e sociedade se influenciam mutuamente. A PC "alimenta" o processo de pesquisa (HILGARTNER, 1990, p. 522) porque possibilita a comunicação dos especialistas com alunos nas práticas em laboratório, com outros especialistas de áreas afins, ou ainda, com agências para o financiamento de pesquisas. Além disso, a PC também é importante para que o público geral possa compreender a construção do conhecimento científico como um processo primariamente social (PARKINSON; ADENDORFF, 2004).

${ }^{3}$ Blank slate, no original. Todas as traduções apresentadas neste estudo são de minha inteira responsabilidade. 
Ao passo que o discurso acadêmico visa convencer o leitor (especialista) acerca da validade de um determinado número de proposiçóes (MYERS, 1989), o discurso das notícias de $\mathrm{PC}$ enfoca as diferentes representações que as pessoas constroem sobre a atividade científica, simulando um debate entre diferentes vozes que se alternam, se contestam ou se coadunam (MOTTA-ROTH; MARCUZZO, 2010, p. 517-518), garantindo a credibilidade do leitor.

A inserção de vozes nas notícias, como recurso de autoridade, para a manutenção da imparcialidade do discurso jornalístico, também pode ser vista como estratégia discursiva para orientar a posição do jornalista com relação ao assunto em discussão (MOTTA-ROTH; MARCUZZO, 2010, p. 532). A PC, desse modo, possui papel relevante na legitimação dos discursos individuais das instituições públicas envolvidas nos debates acerca de determinado tema científico e, em textos de PC, aponta o papel constitutivo da linguagem na negociação de significados e construção de identidades para a manutenção de relações de poder e disputa de mercado no comércio global (HENDERSON et al., 2007, p. 10).

A PC, vista sob esse prisma, engloba diferentes usos da linguagem nas práticas sociais (FAIRCLOUGH, 1992, p. 63) para a produção de diferentes visóes de mundo. É uma ordem do discurso porque situa a ciência na exterioridade, centralizando o papel da mídia na construção de representaçóes sobre a atividade científica e na representação de atores sociais nos textos que apresentam suas interpretações sobre a validade e relevância dos estudos para a sociedade mais ampla. Para a investigação das representações e significados construídos nas notícias de PC, é importante, portanto, uma análise do discurso crítica, que busca tornar mais clara a conexão entre os usos da linguagem e a manutenção ou transformação de estruturas sociais que envolvem relaçóes desiguais de poder.

Para essa análise crítica do discurso, a Linguística Sistêmico-Funcional (HALLIDAY, 1978) oferece um arcabouço teórico no qual a linguagem é concebida como uma rede de significações construídas em função dos contextos de uso (HALLIDAY, 1989, p. 4). A linguagem dos textos de PC (especificamente, o gênero notícia de $\mathrm{PC}$ ) é multifuncional porque reflete e constrói formas de representar, de ser e de agir nos e pelos textos.

Para a investigação das funçōes desempenhadas pela linguagem nas notícias de PC, utilizo a Gramática Sistêmico-Funcional (GSF) (HALLIDAY, 1994, 2004) como ferramenta analítica, com foco na análise dos significados interpessoais nos textos. Nessa análise, enfoco especialmente o sistema de 
Modalidade para a investigação do tom geral do texto (pouca presença de modalidade à maior autoridade do jornalista?) e dos graus de autoridade $\mathrm{e}$ assertividade dos atores sociais representados nos textos (quais marcas de modalidade estão associadas a posições enunciativas específicas, apontando a força ilocucionária dos enunciados?).

\section{Modalidade na Gramática Sistêmico-Funcional}

$\mathrm{Na}$ GSF, o sistema de modalidade (modality) compreende o conjunto de escolhas lexicogramaticais possíveis dentro do sistema da língua para apontar diferentes níveis de certeza e obrigação de um falante com relação a um enunciado (HALLIDAY, 2004, p. 146-147).

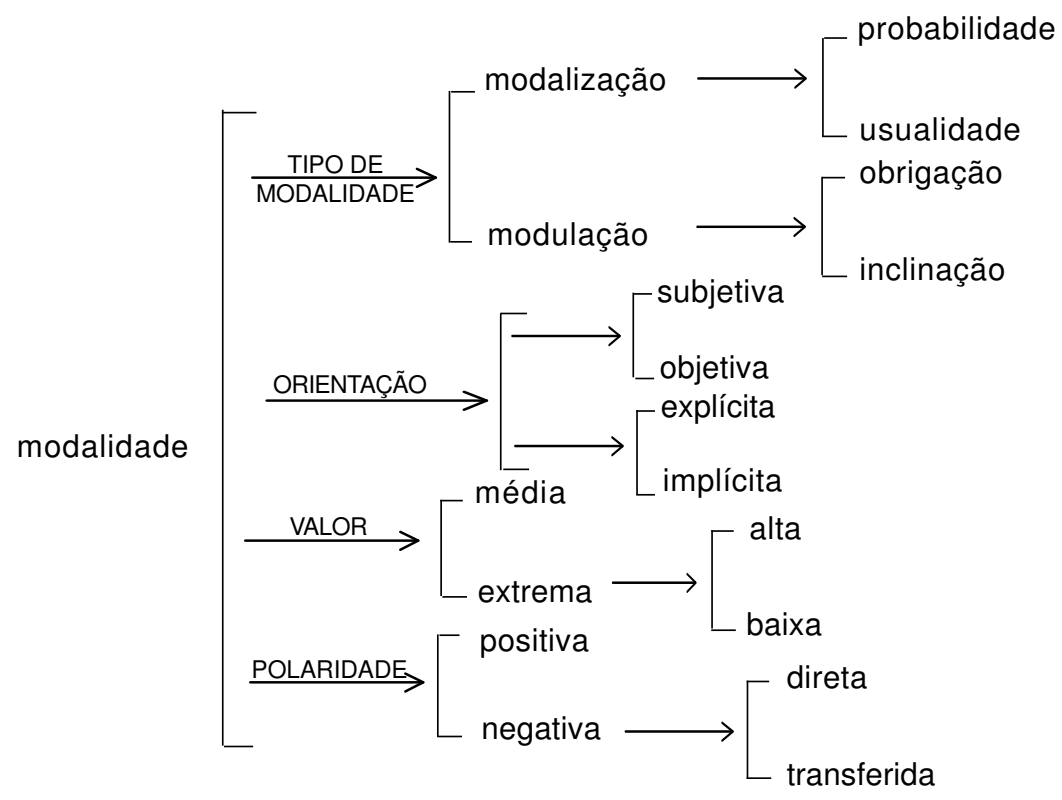

FIGURA 1 - Sistema de modalidade Fonte: HALLIDAY, 2004, p. 150.

No sistema de modalidade descrito por Halliday (FIG. 1), as escolhas lexicogramaticais estão distribuídas em um contínuo entre as polaridades positiva (sim) e negativa (não) e podem ser de duas naturezas: modalização ou modulação.

A modalização é um recurso do sistema linguístico que aponta o grau de veracidade ou credibilidade que aferimos às nossas proposições sobre as coisas do mundo (HALLIDAY, 2004, p. 147). Esse recurso é utilizado nas 
trocas simbólicas entre os falantes, apontando a validade de uma proposição em termos de: a) probabilidade de ela ser mais ou menos verdadeira (ex.: "She may be at home"); ou b) usualidade (frequência) com que ela é verdadeira (ex.: "I always brush my teeth before going to bed") (THOMPSON, 2004, p. 67).

Por outro lado, a modulação é um recurso de linguagem que aponta o comprometimento de um participante na realização de uma ação no mundo, nas trocas de bens e serviços entre os falantes, em termos do: a) grau de inclinação do falante a agir (ex.: "I would help you with your homework") ou b) grau de obrigação do falante na realização de uma ordem ou tarefa (ex.: "You must take care of your children") (THOMPSON, 2004, p. 67).

O valor modal, por sua vez, é o ponto de referência que determina o grau ou frequência de validade de uma proposição ou o grau de comprometimento atribuído ao ouvinte/leitor na aceitação/recusa de uma proposta, apresentando três gradaçôes: alto, médio e baixo. A modalidade, dessa forma, se constitui num caso de dêixis interpessoal, pois "constrói uma região de incerteza onde o próprio falante pode expressar, ou pedir para alguém expressar, uma avaliação acerca da veracidade do que é enunciado" (HALLIDAY, 2004, p. 116). ${ }^{4}$ O QUADRO 1 apresenta os três valores da modalidade distribuídos nos quatro subtipos de modalidade:

\section{QUADRO 1}

Três valores da modalidade

\begin{tabular}{lcccc}
\hline & Probabilidade & Usualidade & Obrigação & Inclinação \\
\hline Alto & certain & always & required & determined \\
Médio & probable & usually & supposed & keen \\
Baixo & possible & sometimes & allowed & willing \\
\hline
\end{tabular}

Fonte: HALLIDAY, 2004, p. 620.

Os graus de assertividade construídos nas notícias de PC podem ser apontados, portanto, pelas escolhas lexicogramaticais em termos de operadores modais finitos (tais como can, may, could, should e must), adjuntos modais (tais como probably, maybe e certainly, willing, keen, determined) e adjetivos de modalidade (tais como certain, possible, probable, required, necessary etc.) que apresentam um valor modal. Entretanto, além dos elementos já apontados para a realização da modalidade, outros expoentes linguísticos podem realizar a

\footnotetext{
${ }^{4}$ No original: "modality construes a region of uncertainty where I can express, or ask you to express, an assessment of the validity of what is being said".
} 
modalidade de modo metafórico, expandindo o campo de significados interpessoais da linguagem.

Um tipo de realização metafórica da modalidade é a metáfora gramatical interpessoal (MGI) - a realização da modalidade por meio de estruturas gramaticais típicas de outros domínios semânticos (HALLIDAY, 2004, p. 592), tais como os processos e participantes da metafunção ideacional. Por exemplo, no enunciado " $\mathrm{He}$ thinks his father got angry with him", a oração projetante (He thinks), constituída de um experienciador ( $H e$ e de um processo mental (thinks) é uma realização metafórica da modalização-probabilidade, indicando um menor grau de assertividade do falante, em comparação com a oração projetante "He knows" (maior assertividade, fato). Ao mesmo tempo, esse tipo de construção distancia o falante de seu enunciado, que é atribuído a outro experienciador $(\mathrm{He})$, diminuindo o grau de responsabilidade modal (THOMPSON, 2004, p. 70) do falante com relação ao julgamento expresso no enunciado.

\section{Metodologia}

O corpus da pesquisa é composto por trinta notícias de PC, selecionadas de acordo com critérios previstos no projeto guarda-chuva (MOTTA-ROTH; LOVATO, 2009, p. 242-243):

1. público-alvo: escritas para uma audiência não especializada;

2. mídia: disponíveis on-line, devido à gratuidade e à acessibilidade;

3. língua: publicações escritas em língua inglesa;

4. período de tempo: publicadas entre 2005 e 2008;

5. conteúdo: notícias que reportam pesquisas científicas relacionadas aos temas transversais de saúde, meio ambiente e tecnologia, conforme os Parâmetros curriculares nacionais (BRASIL, 1997a, 1997b).

As notícias analisadas foram coletadas em duas publicações on-line de PC: 5 BBC News International (BBC) (http://news.bbc.co.uk) e Scientific American (SCIAM) (http://www.scientificamerican.com).

\footnotetext{
${ }^{5}$ O Projeto Guarda-Chuva ainda inclui a análise de notícias de mais duas publicações on-line em inglês (Nature News - http://www.nature.com/news/index.html - e $A B C$ Science - http://www.abc.net.au/science), e duas publicaçôes on-line em português (Ciência Hoje - http://cienciahoje.uol.com.br/revista-ch/2012/290 e Galileu - http:/ /revistagalileu.globo.com. Resultados da análise dos subcorpora em português estão descritos em Lovato (2010) e Motta-Roth e Lovato (2009, 2011).
} 
A seleção das publicações foi realizada por meio de uma análise do contexto de publicação de sites que, provavelmente, publicassem notícias sobre ciência, a partir da experiência do grupo de trabalho do Laboratório de Pesquisa e Ensino de Leitura e Redação (GT-LABLER) na elaboração de material didático em leitura em língua estrangeira (MOTTA-ROTH; LOVATO, 2009, p. 242). Nessa análise, foi investigada, em primeiro lugar, a estrutura dos sites em termos de clareza na delimitação das seçōes, mecanismos de busca de notícias e mission statements - metas ou objetivos da publicação.

A partir dessa análise, foi delimitado o primeiro critério para a seleção das publicaçôes: a presença de, ao menos, uma seção de notícias dedicadas à PC (MOTTA-ROTH; LOVATO, 2009, p. 242). Após essa etapa, foi realizada uma análise da dinâmica de atualização dos sites por meio de uma amostragem por projeção, na qual cada site foi monitorado por aproximadamente dez dias, de forma a verificarmos ${ }^{6}$ o número de notícias publicadas mensalmente e de livre acesso (MOTTA-ROTH; LOVATO, 2009, p. 242). Foram selecionados, portanto, os sites que apresentavam:

a) alta frequência de atualização (com publicação média de quatro notícias por semana); e

b) manutenção do acesso gratuito às notícias por longo espaço de tempo, considerando que alguns deles restringem o acesso após um determinado período, como é o caso da Science (http://www.sciencemag.org).

A pesquisa aqui relatada apresenta um caráter essencialmente qualitativo, com foco na análise detalhada de todos os textos do corpus em termos de (1) identificação e análise da função dos expoentes de modalidade no cotexto em que aparecem e (2) "interpretação semântico-discursiva" dos usos da linguagem em relação à prática social de popularização da ciência (MOTTA-ROTH, 2007, p. 17). Em função desse caráter qualitativo da pesquisa, o corpus analisado é relativamente pequeno, se comparado com pesquisas de linguística de corpus. Por outro lado, adotamos também alguns procedimentos quantitativos, em momentos específicos da análise, para alcançar generalizaçôes que poderiam ser relevantes.

Na etapa da identificação de unidades de análise, foram identificados os expoentes linguísticos da metafunção interpessoal que apontam para os graus de assertividade nas notícias de PC. As unidades consideradas para a análise dos

${ }^{6} \mathrm{O}$ monitoramento e análise dos sites foram realizados pelos membros do GTLABLER. 
textos estão no nível da oração (período simples) e da oração complexa (orações com projeção).

Para a análise da função dos operadores modais nas orações, foi utilizada como ponto de partida a classificação proposta por Biber et al. (1999, p. 485), que distingue três categorias gerais de operadores modais: (1) permissão, possibilidade e habilidade (can, could, may e might); (2) obrigação/necessidade (must e should); e (3) volição/predição (will e would).

$\mathrm{Na}$ MGI, foram analisados os processos nas orações projetantes que, de algum modo, expressam os graus de assertividade dos falantes com relação às proposições, tais como indicate, suggest, believe, show e demonstrate.

De forma a facilitar a análise dos expoentes, foi utilizada a ferramenta "Concordance" do software de análise lexical Wordsmith Tools 5.0 (SCOTT, 2008), a qual não apenas disponibiliza o número de ocorrências de um dado expoente linguístico, mas também mostra cada expoente no contexto da oração e a localização no texto dos expoentes identificados (função "Plot").

$\mathrm{Na}$ etapa de interpretação, tentei explicar os dados obtidos (expoentes linguísticos) em termos dos efeitos de sentido e dos discursos envolvidos na prática social e discursiva de PC.

\section{Discursos de (in)certeza e autoridade nas notícias de PC}

A análise dos graus de autoridade e assertividade no corpus da presente pesquisa sugere que três questôes ou funcionamentos discursivos estão mesclados na construção das notícias de PC:

1) o discurso da mídia na popularização do conhecimento científico visa à manutenção de um ethos imparcial, objetivo e politicamente correto. Para a construção desse ethos, o jornalista utiliza diferentes estratégias discursivas (por meio de diferentes escolhas no sistema linguístico), permitindo que posiçôes de fala alternativas ou opostas tenham voz no debate representado nas notícias, em contraste com as notícias de PC publicadas no início da década de 1990 (NWOGU, 1991). Entretanto, o acesso das vozes da elite (cientistas, técnicos, governo etc.) e do público é desigual nas notícias (MOTTA-ROTH; MARCUZZO, 2010) e, a voz do público, quando presente, parece apenas reforçar prerrogativas já apontadas pela voz do governo;

2) o discurso da ciência na mídia possui o status de autoridade epistêmica e é representado principalmente pela voz do pesquisador que mostra ou encontra evidências objetivamente sobre um determinado fenômeno, conferindo credibilidade aos resultados reportados, e, ao mesmo tempo; 
3) o discurso da ciência na PC evidencia o caráter de incerteza do processo de construção do conhecimento, baseado em hipóteses e explicaçôes temporárias, cabendo aos pesquisadores (em conjunto com colegas) oferecerem explicações coerentes e interpretaçôes cautelosas acerca dos resultados de seus estudos, considerando o histórico de pesquisas prévias em uma determinada área do conhecimento.

Nas próximas subseções, apresento algumas evidências linguísticas que apontam para essas questôes ou funcionamentos discursivos identificados nas notícias da PC.

\section{Discurso da mídia e expansão dialógica nas notícias de PC}

A análise dos graus de autoridade e assertividade nas notícias confirma a posição de insegurança discursiva ocupada pelo jornalista na prática social de PC (MOIRAND, 2003, p. 197). Em vista da dificuldade de checar a validade das informações coletadas e dos diferentes discursos que circulam em torno de um tema científico, ele mobiliza as vozes de diferentes atores sociais, conferindo um caráter aparentemente democrático, aberto e imparcial às notícias.

No entanto, a "insegurança discursiva" também pode ser vista como a oscilação do jornalista de PC entre opinião e informação, ao preferir inserir fragmentos das palavras proferidas por outros em vez de aderir a sua função específica de popularizar a ciência (BEACCO et al., 2002, p. 281), o que pode ser interpretado como uma oscilação entre o discurso técnico coletado junto às fontes científicas (o pesquisador e colegas) e o discurso jornalístico que oferece uma versão popular do discurso técnico.

De forma que a mobilização de vozes seja possível nos textos, os enunciados nas notícias de PC devem apresentar um baixo comprometimento modal, em outras palavras, um baixo grau de comprometimento das vozes com relação aos julgamentos de validade, permitindo, assim, uma expansão dialógica nos textos (MARTIN; WHITE, 2005, p. 96). A expansão dialógica mostra a solidariedade do jornalista com pontos de vista alternativos que dialogam entre si (BAKHTIN, 2006). O uso da modalidade nos textos, para indicar indeterminação, incerteza nos enunciados, consiste, desse modo, em "construir um contexto comunicativo heteroglossicamente diverso e se engajar de diferentes maneiras com essa diversidade" (WHITE, 2003, p. 280). ${ }^{7}$

\footnotetext{
${ }^{7}$ No original: "to construe the communicative context as heteroglossically diverse and to engage in different ways with that diversity."
} 
O baixo comprometimento modal nos enunciados é revelado, principalmente, pela análise do valor modal dos operadores modais finitos, confirmando a análise prévia das notícias da BBC (NASCIMENTO, 2010). $\mathrm{Na}$ presente análise (incluindo notícias da SCIAM), 63\% dos operadores modais apresentam baixo valor modal (can, could, may e might), $32 \%$ médio valor modal (will, would e should) e apenas $5 \%$ alto valor modal (must).

Exemplo $1-$ may $^{8}$

"Inactivity may diminish life expectancy not only by predisposing to agingrelated diseases but also because it may influence the aging process itself." $(\text { SCIAM\# } 12)^{9}$

Exemplo 2-could

"For HD 149026 b to reach such blistering heat, researchers say, it must suck up nearly all the energy it receives from its big bluish star. If so, the gaseous planet could be nearly pitch-black in color." (SCIAM\#6)

Exemplo 3-could

"If the CD117 cell population does lead to tumor initiation or cancer reoccurrence, this cell marker could become a therapeutic target," she says [says Leisa Johnson, a molecular biologist at Genentech, Inc., in South San Francisco, Calif]. (SCIAM\#4)

Os exemplos 1 a 3 apresentam enunciados com especulações (may, could) acerca dos resultados das pesquisas e possibilidades de aplicação das descobertas. Nos exemplos 1 e 2, o caráter de possibilidade é apontado pelo operador modal may. Nos exemplos 2 e 3 , os pesquisadores fazem predições a partir dos resultados preliminares dos estudos, nos quais o operador modal could aparece geralmente associado a uma oração condicional (iff).

Apesar do baixo grau de comprometimento modal predominante nos textos, o jornalista, inicialmente, capta a atenção do público, geralmente enunciando fatos no título das notícias:

\footnotetext{
${ }^{8}$ Ao longo dos exemplos descritos no presente estudo, utilizo negrito como primeira ênfase e sublinhado como segunda ênfase.

${ }^{9}$ Os textos do corpus são identificados pelas siglas BBC e SCIAM (BBC News e Scientific American, respectivamente), acompanhadas do sinal \# para designar o número do texto (1 a 15$)$.
} 


\section{QUADRO 2}

Títulos das notícias de PC da BBC

\begin{tabular}{ll}
\hline Notícia & Título \\
\hline BBC\#1 & Home birth to ward increases risk \\
BBC\#2 & HIV 'hides from drugs for years' \\
BBC\#4 & Study finds benefits in GM crops \\
BBC\#5 & Racial clues in bowel cancer find \\
BBC\#6 & Brain size 'not key to intellect' \\
BBC\#7 & Gene 'controls body fat levels' \\
BBC\#8 & Fat scan shows up 'true' obesity \\
BBC\#10 & Berries 'help prevent dementia' \\
BBC\#12 & Gene 'links breastfeeding to IQ' \\
BBC\#15 & NHS staff dub e-records 'clunky' \\
\hline
\end{tabular}

QUADRO 3

Títulos das notícias de PC da SCIAM

\begin{tabular}{ll}
\hline Notícia & Título \\
\hline SCIAM\#1 & When It Comes to Photosynthesis, Plants Perform Quantum Computation \\
SCIAM\#2 & Whole Lotta Shakin' on Asteroid Itokawa \\
SCIAM\#5 & Mathematics Points the Way to a Perfect Head of Beer \\
SCIAM\#7 & Genetically Modified Crops Survive Weed-Whacking Herbicide \\
SCIAM\#10 & That Flu You Caught? It Came from East and Southeast Asia \\
SCIAM\#11 & Monkey Think, Robot Do \\
SCIAM\#12 & Work It Out: More Activity = Slower Aging \\
SCIAM\#13 & Wireless Energy Lights Bulb from Seven Feet Away \\
\hline
\end{tabular}

Os títulos descritos nos QUADROS 2 e 3 apresentam modalidade categórica (FAIRCLOUGH, 2003, p. 159), em outras palavras, asserções que constroem a experiência em termos de categorizações absolutas, no nível da polaridade (sim ou não). A modalidade categórica nos títulos parece se constituir em uma visada de captação (CHARAUDEAU, 2009, p. 91), de forma a conquistar antecipadamente o interesse do leitor sobre a notícia. Os títulos, ao apresentarem "fatos" ou "verdades" definitivas, produzem desse modo um efeito de dramatização nos enunciados.

Em um segundo momento, geralmente no lide, o jornalista utiliza estratégias discursivas de forma a não se responsabilizar pela validade das proposições, atribuindo-as ao pesquisador-autor do estudo reportado. 


\section{QUADRO 4}

Exemplos de lide das notícias de PC da BBC

\begin{tabular}{lll}
\hline Texto & Oração projetada (proposição) & Oração projetante \\
\hline BBC\#9 & $\begin{array}{l}\text { Alzheimer's drugs currently being denied to } \\
\text { some NHS patients may have a dramatic } \\
\text { impact on the pathology of the brain, } \\
\text { Dementia could be slowed significantly by } \\
\text { treatments which reset the body's natural clock, } \\
\text { BBC\#11 }\end{array}$ & $\begin{array}{l}\text { research in the UK } \\
\text { indicates. } \\
\text { to brain evolution, }\end{array}$ \\
BBC\#1 & $\begin{array}{l}\text { There may be serious risks for the baby when have said. } \\
\text { mothers who chose a home birth are transferred } \\
\text { to hospital, }\end{array}$ & say experts. \\
BBC\#12 & $\begin{array}{l}\text { Compounds in the common British blackcurrant } \\
\text { could help prevent Alzheimer's disease, }\end{array}$ & research suggests. \\
\hline
\end{tabular}

Nas construções descritas no QUADRO 4, os operadores modais realizam a modalidade de modo subjetivo nas oraçôes projetadas, de modo a enfatizar os resultados da pesquisa e atrair a atenção do leitor. Por outro lado, a oração projetante, em segundo plano, realiza a modalidade de modo explícito, de forma a diminuir a responsabilidade modal do escritor (ou da corporação $\mathrm{BBC}$, no caso das notícias onde o autor não é mencionado), atribuindo a responsabilidade pelo julgamento apresentado a uma fonte, enfatizando o envolvimento subjetivo da posição enunciativa do pesquisador-autor do estudo na construção do texto. Nos textos, a referenciação à voz dessa posição é geralmente realizada por meio de personificações e metonímias, tais como "This study confirms" (SANTOS, 2007, p. 16), que se constituem em recursos de objetividade utilizados pelo jornalista.

Ao longo do texto, o jornalista também mistura a sua própria voz às vozes dos outros atores sociais (principalmente o pesquisador), apresentando o mesmo grau de assertividade da fonte:

Exemplo 4

"Transfers" did not refer exclusively to women who were rushed to hospital in labour, but included any woman who, having initially chosen a home birth at 12 weeks, ended up giving birth in hospital.

The reasons were also unknown, potentially varying from a change of heart or the desire for more effective pain relief to a major complication. 


\section{And the actual numbers are small. [...]}

The National Childbirth Trust, which wants all women to have the choice of a home birth, says the study should have looked at the number of babies who died in hospital after their mothers developed complications. [...]

The Royal College of Midwives said the research was "welcome but inconclusive". [...] (BBC\#1)

No exemplo 4, o jornalista faz afirmações categóricas acerca das limitações do estudo sobre os riscos do parto caseiro na Inglaterra, não atribuindo, inicialmente, as informações a uma fonte externa. $\mathrm{O}$ jornalista, nesse caso, guia a interpretação do leitor com relação ao grau de probabilidade dos resultados reportados. Entretanto, na sequência do texto, ele insere vozes de outras posições enunciativas de autoridade (pesquisadores-colegas, técnicos etc.), que endossam o julgamento construído por ele anteriormente, conferindo credibilidade ao ponto de vista construído (WHITE, 2003, p. 270).

Além disso, quando a voz do jornalista se faz visível, ela tende a apresentar um grau de assertividade semelhante ao das fontes (VARTALLA, 1999, p. 185) na apresentação dos principais resultados da pesquisa:

Exemplo 5 - Jornalista + Pesquisador

Warning, couch potatoes: resting on your laurels may be hazardous to your health, not to mention make you old before your time.

"A sedentary lifestyle increases the propensity to aging-related disease and premature death," researchers at King's College London report today in the journal Archives of Internal Medicine. "Inactivity may diminish life expectancy not only by predisposing to aging-related diseases but also because it may influence the aging process itself." (SCIAM\#12)

No exemplo 5, a voz do jornalista se faz visível pelo uso do vocativo (couch potatoes) e do pronome da 2a pessoa (your) (MOTTA-ROTH, 2009, p. 182). Ao alertar o leitor sobre os riscos da inatividade para a saúde humana (Warning, couch potatoes...), ele apresenta o mesmo baixo grau de assertividade dos pesquisadores com relação aos resultados do estudo, sinalizado pelo operador modal may.

O discurso da mídia na PC reflete, portanto, o papel do jornalista de informar e explicar o significado e a relevância das pesquisas para audiências que não participam da esfera científica (MOTTA-ROTH, 2009, p. 139). Para a realização dessa função, ele faz eco às vozes do pesquisador e pesquisadorcolega/técnico/instituição ao longo dos textos, de forma a preservar a 
autoridade dos cientistas ou utilizá-la para ratificar seu posicionamento frente aos resultados da pesquisa reportada.

\section{Discurso da ciência na notícia de PC}

Nas notícias de PC analisadas, o discurso da ciência é representado pela voz da jornalista e dos pesquisadores-colegas/técnicos, desempenhando as funções de informar, explicar e avaliar o conhecimento científico popularizado (MOTTA-ROTH; MARCUZZO, 2010, p. 530). Ao desempenharem essas funçóes, esses atores sociais apontam ao leitor quais informaçōes devem ser interpretadas como conhecimento estabelecido ou como especulação, hipótese:

Exemplo 6-Pesquisador-colega

"Essentially women who opt for a home birth face either a very successful, satisfying outcome, or a potentially disastrous one - there isn't the greyer area that you see with hospital births," says Professor Philip Steer, the editor of the BJOG. (BBC\#1)

Exemplo 7 - Pesquisador-autor

Lead researcher Dr Jonathan Graff said: "From worms to mammals, this gene controls fat formation."

"It could explain why so many people struggle to lose weight, and suggests an entirely new direction for developing medical treatments that address the current epidemic of diabetes and obesity.

"Maybe if you could affect this gene, even just a little bit, you might have a beneficial effect on fat." (BBC\#7)

Exemplo 8 - Pesquisador-autor

"One other aspect of the electricity pathway is that most emissions are concentrated in one location, which provides perhaps an opportunity for more control of the emissions," Campbell notes. "It also perhaps locates [other air pollution] emissions in a place where impacts might not be as harmful as where cars are driven today." (SCIAM\#3)

No exemplo 6, há um adjunto de comentário, essentially, e uma oração com modalidade categórica ("women who opt for a home birth face either a very successful, satisfying outcome, or a potentially disastrous one") que, juntamente com uma proposição polarizada negativamente (there isn't), indicam o alto grau de certeza do pesquisador-colega. Por outro lado, nos exemplos 7 e 8 , as proposições dos pesquisadores são modalizadas por meio 
de operadores modais (might, could), adjuntos de modo (maybe, perhaps) e processo na MGI (suggests) que indicam possibilidade, hipótese.

Exemplo 9-Pesquisador-autor

An examination of over 5,000 teeth from early human ancestors shows that many of the first Europeans probably came from Asia. (SCIAM\#8)

Exemplo 10 - Pesquisador-autor

A new study shows music instruction may improve language-processing skills by altering the brain stem (SCIAM\#9)

Nos exemplos 9 e 10, o processo, show, aponta um alto grau de assertividade, comprometendo os pesquisadores (o estudo) pelos resultados anunciados, mas, ao mesmo tempo, outros elementos da linguagem (adjunto e operador modal) modalizam as proposições, diminuindo o grau de certeza. As pesquisas, portanto, "mostram" resultados que ainda não são definitivos.

Em contraste, a participação do público nas notícias é facultativa, considerando que essa posição enunciativa não desempenha um papel decisivo nos debates, mas somente aquele de reivindicação ou de testemunha (CHARAUDEAU, 2009, p. 194),$^{10}$ expressando vontade de decisão e ratificando o posicionamento anunciado/prometido pelo governo no debate:

Exemplo 11

More than half of Britons who took part in the "GM Nation" survey last year said GM crops should never be introduced in the UK under any circumstances. (BBC\#4)

No exemplo 11, o processo não marcado say introduz uma reivindicação do público no debate sobre a introdução de sementes geneticamente modificadas na Inglaterra. Essa reivindicação é sinalizada pelo operador modal should em combinação com o adjunto de usualidade, never, que apontam o alto grau de autoridade do falante.

Nas notícias de PC analisadas, o discurso da ciência ainda funciona em uma lógica tradicional ou empirista, na qual a produção do conhecimento é

${ }^{10}$ Outras publicações de PC on-line (como no caso da Science Daily, disponível em $<$ http://www.sciencedaily.com/videos/2006/0201-waking_up_teens.htm>) dão maior visibilidade à voz do público, por meio de depoimentos de pessoas que participaram do experimento científico relatado, atuando como testemunhas no discurso e, desse modo, influenciando a credibilidade das informações. 
vista como um “jogo" em que uma hipótese ou teoria passa por uma sucessão de testes até que possa ser validada, aceita numa comunidade científica (POPPER, 1959, p. 53-54). Nesse jogo, a análise da "realidade" gera afirmações parciais, particulares, que possibilitam previsóes ou hipóteses sobre outros fenômenos ainda não conhecidos ou descritos pela ciência (POPPER, 1959, p. 60). Entretanto, o processo de construção e corroboração (confirmação) de teorias e hipóteses representado no jogo discursivo das notícias de PC contraria a crença comum de uma ciência "objetiva" que desconsidera o envolvimento do pesquisador no processo de investigação (GILBERT; MULKAY, 1984, p. 56 citado por SWALES, 1990, p. 123).

Em resumo, as notícias de PC analisadas neste estudo apresentam uma oscilação entre o discurso jornalístico, que visa à construção de um efeito de imparcialidade, e o discurso científico como discurso de autoridade, personificado pelos pesquisadores e pesquisadores-colegas que apresentam diferentes graus de assertividade em suas proposiçóes, apontando a probabilidade das descobertas relatadas. $\mathrm{O}$ uso de elementos de modalidade nas notícias deve, portanto, ser visto como um fenômeno "polipragmático" (HYLAND, 1996, p. 437); em outras palavras, os índices linguísticos analisados realizam múltiplas funções nos enunciados:

a) apontam o grau de validade das proposições (precisão) ou tornam as informações imprecisas e ambíguas, por meio de uma combinação de índices linguísticos (operadores e adjuntos modais, processos verbais e mentais na MGI, adjetivos de modalidade) que é específica e possui significado no contexto da oração complexa ou do texto;

b) antecipam o julgamento de aceitabilidade do leitor, como estratégia de polidez negativa tipicamente usada no discurso acadêmico, de forma a proteger os jornalistas de possíveis críticas ao conteúdo das notícias (CROMPTON, 1997, p. 275-276); e/ou

c) aumentam o efeito retórico dos textos perante a audiência não especialista, como estratégia de polidez positiva (MYERS, 1989, p. 28), ao imitarem o estilo dos gêneros acadêmicos (VARTALLA, 1999, p. 132), por meio do uso de expressóes tais como evidence suggests, a study indicates etc. 


\section{Considerações finais}

A análise dos expoentes apontando graus de assertividade nas posições enunciativas confirmou resultados prévios da análise crítica do gênero notícia de PC (MARCUZZO, 2008, 2009, 2011; MOTTA-ROTH, 2009; MOTTA-ROTH; MARCUZZO, 2010; MOTTA-ROTH; LOVATO, 2011; SILVA, 2010), sugerindo que a ciência (e o cientista, como representante da esfera social acadêmica) ocupa uma posição privilegiada dentre os discursos que circulam na ordem discursiva da PC.

Nas notícias de PC analisadas, o cientista-autor do estudo reportado é $o$ ator social que possui autoridade para explicar o conhecimento científico para uma audiência não especializada, apontando ao leitor o grau de "precisão" acerca da validade de uma descoberta, acomodando hipóteses em relação ao conhecimento já estabelecido sobre um tópico de pesquisa. $\mathrm{O}$ pesquisadorcolega/técnico/instituição, por sua vez, avalia a pesquisa reportada em termos da metodologia empregada e oferece outras interpretaçóes para os resultados reportados. O governo, por outro lado, não possui papel relevante na discussão acerca da validade dos resultados de uma pesquisa, mas faz recomendaçōes/ sugestōes para a população a partir desses resultados, principalmente quando a notícia trata questôes já consagradas pela mídia, armazenadas na memória interdiscursiva (BEACCO et al., 2002) dos leitores, tais como a prevenção do vírus HIV e a manipulação genética de sementes. O público, por sua vez, faz reivindicações, reforçando as recomendações apresentadas pelo governo.

Contrariando uma visão tradicional de PC, a função primordial do jornalista nas notícias não é "simplificar" o conhecimento científico para uma audiência não especializada, mas promover o interesse do leitor e familiarizálo com as descobertas científicas relatadas. Desse modo, as descobertas são debatidas em função do contexto sócio-histórico de publicação, fazendo referência aos discursos correntes na mídia em uma determinada época (MYERS, 2003, p. 272).

Entretanto, a ciência vivenciada pelo público no cotidiano não serve para legitimar ou questionar as descobertas relatadas, apesar do discurso público na mídia se constituir numa poderosa estratégia ideológica para a construção de determinadas interpretaçôes sobre as descobertas.

Membros do público que desafiam afirmações científicas nunca terão o mesmo tipo de autoridade dos cientistas porque eles não são capazes de utilizar as mesmas redes de suporte (conceitual) para suas afirmações (Latour, 1987). [...] Mas membros do público possuem 
seus próprios recursos persuasivos, porque eles podem conectar as abstrações do conhecimento científico com a experiência vivida, e os debates públicos fornecem seus próprios tipos de questionamento aos argumentos. (MYERS, 2003, p. 269). ${ }^{11}$

A prática social de PC, instanciada nas notícias do corpus analisado, ainda reflete, portanto, uma prática tradicional de didatização do conhecimento científico (nos termos de BEACCO et al., 2002), considerando o papel de autoridade dos cientistas e o importante papel do jornalista, que atua como mediador no processo de recontextualização do conhecimento científico.

Com relação à análise dos textos, encontrei dificuldade na descrição dos expoentes identificados devido à complexidade de categorias da linguagem que podem realizar modalidade, mais precisamente 144 categorias (HALLIDAY, 2004, p. 621). Além disso, significados interpessoais podem ser expressos de inúmeras maneiras pela linguagem e nem sempre é possível identificar quais são representações metafóricas de modalidade:

Nem sempre é possível dizer exatamente o que é e o que não é uma representação metafórica de uma modalidade. Mas os falantes possuem infinitas maneiras de expressar suas opiniōes - ou, mais que isso, talvez, de dissimular suas opiniōes. (HALLIDAY, 2004, p. 616). ${ }^{12}$

Consequentemente o longo tempo empenhado na identificação dos expoentes limitou severamente o tamanho do corpus (trinta notícias de PC da $\mathrm{BBC}$ e da SCIAM), impossibilitando a análise de mais trinta notícias ( $A B C$ Science e Nature) previstas no projeto PQ-CNPq dentro do tempo disponível para a realização da pesquisa. $\mathrm{O}$ tamanho reduzido do corpus analisado pode ser visto, portanto, como uma limitação em termos de poder de generalização dos resultados da pesquisa.

${ }^{11}$ No original: "Members of the public who challenge scientific claims will never have the same sort of authority as scientific experts, because they cannot marshal the same networks of support for their claims (Latour, 1987). [...] But members of the public have their own persuasive resources, because they can connect the abstractions of scientific knowledge to lived experience, and public debates provide their own sorts of challenges to arguments."

${ }^{12}$ No original: "It is not always possible to say exactly what is and what is not a methaphorical representation of a modality. But speakers have indefinitely many ways of expressing their opinions - or rather, perhaps, of dissimulating their opinions." 
Além da ampliação do corpus, percebo a necessidade de três futuras pesquisas, tendo em vista ampla variedade de gêneros discursivos envolvidos no processo de PC: 1) analisar os graus de assertividade em notícias de PC em português; 2) desenvolver um estudo comparativo dos graus de assertividade entre a notícia de PC na mídia de massa e o artigo acadêmico do qual ela se origina; e 3) analisar os graus de assertividade nos livros didáticos sobre ciência utilizados na escola. Acredito que um maior conhecimento sobre o processo de $\mathrm{PC}$ e os gêneros discursivos envolvidos pode contribuir substancialmente para uma expansão das competências de leitura e escrita em ciências ensinadas na escola e, desse modo, possibilitar o desafio de uma prática científica hegemônica, exclusivista e autoritária.

\section{Referências}

BAKHTIN, M. M. Estética da criação verbal. Tradução de Paulo Bezerra. 4. ed. São Paulo: Martins Fontes, 2006.

BEACCO, J.; CLAUDEL, C.; DOURY, M.; PETIT, G.; REBOULD-TOURÉ, S. Science in Media and Social Discourse: New Channels of Communication, New Linguistic Forms. Discourse Studies, v. 4, n. 3, p. 277-300, 2002.

BIBER, D.; JOHANSSON, S.; LEECH, G.; CONRAD, S.; FINEGAN, E. Longman Grammar of Spoken and Written English. London: Longman, 1999.

BRASIL. Ministério da Educação. Parâmetros curriculares nacionais: introdução aos parâmetros curriculares nacionais. Brasília: Ministério da Educação; Secretaria de Estado de Fazenda, 1997a. Disponível em: <http://mecsrv04.mec. gov.br/sef/estrut2/pcn/pdf/livro01.pdf>. Acesso em: 21 fev. 2006.

BRASIL. Ministério da Educação. Parâmetros curriculares nacionais: saúde. Brasília: Ministério da Educação; Secretaria de Estado de Fazenda, 1997b. Disponível em: <http://mecsrv04.mec.gov.br/sef/estrut2/pcn/pdf/livro092.pdf>. Acesso em: 12 mar. 2007.

CALSAMIGLIA, H. Popularization Discourse. Discourse Studies, v. 5, n. 2, p. 139-146, May 2003.

CALSAMIGLIA, H.; LÓPEZ FERRERO, C. Role and Position of Scientific Voices: Reported Speech in the Media. Discourse Studies, v. 5, n. 2, p. 147-173, May 2003.

CALSAMIGLIA, H.; VAN DIJK, T. A. Popularization Discourse and Knowledge about the Genome. Discourse \& Society, v. 15, n. 4, p. 369-389, Jul. 2004.

CHARAUDEAU, P. Discurso das mídias. São Paulo: Contexto, 2009. 
CROMPTON, P. Hedging in Academic Writing: Some Theoretical Problems. English for Specific Purposes, v. 16, n. 4, p. 271-287, 1997.

FAIRCLOUGH, N. Analysing Discourse: Textual Analysis for Social Research. London; New York: Routledge, 2003.

FAIRCLOUGH, N. Discourse and Social Change. Cambridge (UK): Polity, 1992.

GEE, J. P. An Introduction to Discourse Analysis: Theory and Method. London: Routledge, 2000.

HALLIDAY, M. A. K. An Introduction to Functional Grammar. 2. ed. London; Melbourne; Auckland: Edward Arnold, 1994.

HALLIDAY, M. A. K. An Introduction to Functional Grammar. 3. ed. London; Melbourne; Auckland: Edward Arnold, 2004.

HALLIDAY, M. A. K. Language as Social Semiotic: The Social Interpretation of Meaning. London: Edward Arnold, 1978.

HALLIDAY, M. A. K. Part A. In: .; HASAN, R. Language, Context, and Text: Aspects of Language in a Social-Semiotic Perspective. Oxford: Oxford University Press, 1989. p. 3-49.

HENDERSON, A.; WEAVER; C. K.; CHENEY, G. Talking "Facts": Identity and Rationality in Industry Perspectives on Genetic Modification. Discourse Studies, v. 9, n. 1, p. 9-41, Feb. 2007.

HILGARTNER, S. The Dominant View of Popularization: Conceptual Problems, Political Uses. Social Studies of Science, v. 20, n. 3, p. 519-539, Aug. 1990. Disponível em: <http://www.dgdc.unam.mx/Assets/pdfs/sem_hilgartner.pdf>. Acesso em: 8 ago. 2012.

HYLAND, K. Writing Without Conviction: Hedging in Science Research Articles. Applied Linguistics, v. 17, n. 4, p. 433-454, Dec. 1996.

LEITE, M. A contribuição do Jornalismo Científico ao desenvolvimento científico brasileiro. Disponível em: <http://www.jornalismocientifico.com.br/jornalismo cientifico/artigos/jornalismo_cientifico/artigo10.php>. Acesso em: 14 nov. 2007.

LOVATO, C. dos S. Análise de gênero: investigação da organização retórica de notícias de popularização da ciência na revista Ciência Hoje Online. 2010. 102 f. Dissertação (Mestrado em Letras) - Programa de Pós-Graduação em Letras, Universidade Federal de Santa Maria, Santa Maria, 2010.

MARCUZZO, P. A polifonia em notícias de popularização científica. Santa Maria, Programa de Pós-Graduação em Letras, Universidade Federal de Santa Maria, 2008. Trabalho final da disciplina "Teorias de Gêneros Discursivos" (PPGLET812). Não publicado. 
MARCUZZO, P. Ciência em debate? Uma análise das vozes no gênero notícia de popularização científica. 173 f. 2011. Tese (Doutorado em Estudos Linguísticos) - Programa de Pós-Graduação em Letras, Universidade Federal de Santa Maria, Santa Maria, 2011.

MARCUZZO, P. O jogo de vozes em notícias de popularização da ciência. In: MOTTA-ROTH, D.; GIERING, M. E. (Org.). HIPERS@BERES - Discursos de popularização da ciência. Santa Maria: PPGL Editores, 2009, v. 1, p. 90-100. Disponível em: <http://w3.ufsm.br/hipersaberes/volumeI>. Acesso em: $31 \mathrm{dez}$. 2009.

MARTIN, J. R.; WHITE, P. R. R. The Language of Evaluation: Appraisal in English. London; New York: Palgrave Macmillan, 2005.

MEDEIROS, R. O conhecimento socializado e o papel do jornalismo no contexto da divulgação da ciência. In: SOUSA, C. M.; PERIÇO, N. M.; SILVEIRA, T. S. (Org.). A comunicação pública da ciência. Taubaté: Cabral; Livraria Universitária, 2003. p. 79-93.

MOIRAND, S. C. Communicative and Cognitive Dimensions of Discourse on Science in the French Mass Media. Discourse Studies, v. 5, n. 1, p. 175-206, 2003.

MOTTA-ROTH, D. A popularização da ciência como prática social e discursiva. In: MOTTA-ROTH, D.; GIERING, M. E. (Org.).HIPERS@BERES Discursos de popularização da ciência. Santa Maria: PPGL Editores, v. 1, p. 130195, 2009. Disponível em: <http://w3.ufsm.br/hipersaberes/volumeI>. Acesso em: 31 dez. 2009.

MOTTA-ROTH, D. Análise crítica de gêneros com foco em artigos de popularização da ciência. Projeto de Produtividade em Pesquisa PQ/CNPq (no 301962/20073), 2007. Disponível em: <http://coralx.ufsm.br/desireemroth/Projeto_ Comite_Etica.pdf $>$. Acesso em: Acesso em: 31 dez. 2007.

MOTTA-ROTH, D.; LOVATO, C. dos S. O poder hegemônico da ciência no discurso de popularização científica. Calidoscópio, São Leopoldo, v. 9, n. 3, p. 251-268, 2011.

MOTTA-ROTH, D.; LOVATO, C. dos S. Organização retórica do gênero notícia de popularização da ciência. Linguagem em (Dis) curso, Tubarão, v. 9, n. 2, p. 233-271, 2009.

MOTTA-ROTH, D.; MARCUZZO, P. Ciência na mídia: análise crítica de gênero de notícias de popularização científica. Revista Brasileira de Linguística Aplicada, Belo Horizonte, v. 10, n. 3, p. 511-538, 2010. 
MOTTA-ROTH, D.; MARCUZZO, P; NASCIMENTO, F. S.; SCHERER, A. S. Polifonia em notícias de popularização da ciência sob a ótica sistêmicofuncional. In: CONGRESSO DA ASSOCIAÇÃO DE LINGUÍSTICA SISTÊMICO-FUNCIONAL DA AMERICA LATINA, 4., 2008, Florianópolis. Anais... Florianópolis: ALSFAL-UFSC, 2008.

MYERS, G. Discourse Studies of Scientific Popularization: Questioning the Boundaries. Discourse Studies, v. 5, n. 2, p. 265-279, 2003.

MYERS, G. The Pragmatics of Politeness in Scientific Articles. Applied Linguistics, v. 10, n. 1, p. 1-35, 1989.

NASCIMENTO, F. S. 'GM crops may be harmful to the environment': graus de autoridade e assertividade em notícias de popularização da ciência. 2011. 114 f. Dissertação (Mestrado em Letras) - Universidade Federal de Santa Maria, Santa Maria, 2011.

NASCIMENTO, F. S. Modalização como fenômeno discursivo em notícias de popularização da ciência. Investigaçôes, Recife, v. 23, n. 2, p. 65-98, jul. 2010.

NWOGU, K. N. Structure of Science Popularizations: A Genre-Analysis Approach to the Schema of Popularized Medical Texts. English for Specific Purposes, v. 10, n. 10, p. 111-123, 1991.

PARKINSON, J.; ADENDORFF, R. The Use of Popular Science Articles in Teaching Scientific Literacy. English for Specific Purposes, v. 23, n. 4, p. 379-396, 2004.

PAUL, D. Spreading Chaos: The Role of Popularizations in the Diffusion of Scientific Ideas. Written Communication, v. 21, n. 1, p. 32-68, Jan. 2004.

POPPER, K. The Logic of Scientific Discovery. New York: Harper, 1959.

PRATES, N. D.; SCHERER, A. S.; MOTTA-ROTH, D. Organização retórica e uso de aposto em artigos de popularização da ciência. In: SEMINÁRIO DO GEL - GRUPO DE ESTUDOS LINGUÍSTICOS, 56., 2008, São José do Rio Preto. Resumos eletrônicos... São José do Rio Preto: Grupo de Estudos Linguísticos/UNIP; UNESP, 2008. Disponível em: <http://www.gel.org.br/ resumos_det.php?resumo=4934> Acesso em: 12 dez. 2009.

SANTOS, R. L. dos. Metonímias e personificações da popularização científica: um estudo das notícias do BBC News International. Vidya, v. 27, n. 2, p. 8598, Jul.-Dec. 2007.

SCOTT, M. WordSmith Tools version 5. Liverpool: Lexical Analysis Software, 2008.

SEGUIN, E. Narration and Legitimation: The Case of In Vitro Fertilization. Discourse \& Society, v. 12, n. 2, p. 195-215, 2001. 
SILVA, E. A. What Social Actors Say and How They Do It in the Science Popularization New Genre. Santa Maria, Departamento de Letras Estrangeiras Modernas, 2010. Trabalho final de graduação. Não publicado.

SWALES, J. Genre Analysis: English in Academic and Research Settings. Cambridge (UK): Cambridge University Press, 1990.

THOMPSON, G. Introducing Functional Grammar. 2. ed. London: Arnold, 2004.

VARTALLA, T. Remarks on the Communicative Functions of Hedging in Scientific and Specialist Research Articles on Medicine. English for Academic Purposes, v. 18, n. 2, p. 177-200, Jun. 1999.

WHITE, P. R. R. Beyond Modality and Hedging: A Dialogic View of the Language of Intersubjective Stance. Text, v. 23, n. 2, p. 259-284, 2003. Disponível em: <http://grammatics.com/appraisal/textSpecial/beyondmodality(white).pdf>. Acesso em: 8 ago. 2012.

Recebido em 14/03/2012. Aprovado em 01/07/2012. 